\title{
Editorial
}

\section{GASTROINTESTINAL MUCOSAL PROTECTION}

\author{
Siddiqui $\mathrm{AM}^{1}$
}

Various medications play an important role in the development of peptic ulcer disease and acute upper gastrointestinal (GI) bleeding ${ }^{1,2}$. Gastric erosion due to nonsteroidal anti-inflammatory drugs (NSAIDs) is the second most important cause of acute upper GI bleeding after peptic ulcer disease. The mortality of acute upper GI bleeding remains around 10 percent, in spite of various therapeutic options available. Aspirin and NSAIDs cause gastrointestinal erosions and ulcer especially in elderly patients and a significant proportion of these patients develop bleeding ${ }^{3}$. Aspirin even 30-75 mg a day can produce gastric erosions. Corticosteroid in the usual therapeutic doses probably has no influence on GI haemorrhage. Anticoagulants do not cause acute GI haemorrhage but risk of bleeding is greater if the patient is on anticoagulants therapy ${ }^{4}$. In spite strong support infavour of increased risk in elderly, some study observed that aspirin induced damage to stomach was weakly related to dose and older age did not increase the risk of erosions ${ }^{5}$.

Aspirin and other NSAIDs deplete mucosal prostaglandins by inhibiting the cyclo-oxygenase (COX) pathway which leads to mucosal damage. Cyclooxygenase occurs in two main forms: COX-1, the constitutive enzyme and COX-2, the inducible form which is produced by cytokine stimulation in area of inflammation ${ }^{1}$. Mechanisms by which NSAIDs may induce mucosal injury include :

- Endothelial effects: Stasis-Ischaemia-Ulceration

- Direct toxicity to trapping leading to ulceration

Epithelial effects due to prostaglandin depletion

NSAIDs increase $\mathrm{HCl}$ secretion, reduce mucin, reduce $\mathrm{HCO}_{3}$, reduce surface active phospholipids secretion and reduce epithelial cell proliferation. All these lead to mucosal damage.

Fifty percent of patients on regular aspirin develop gastric mucosal damage and approximately $30 \%$ show ulcer on endoscopic examination. Only a small portion of patients have symptoms (about 5\%) and only 1-2\% develops GI bleeding ${ }^{1}$. For established ulcer proton pump inhibitor (PPI) is the best treatment. Prophylactic cytoprotective therapy of PPI or misoprostol is effective for all high risk patients over 65 years of age, those with a peptic ulcer history particularly with complications and patients on therapy with corticosteroid or anticoagulants ${ }^{6}$.

Ranitidine blocks the $\mathrm{H}_{2}$-receptor, one of the pathways of gastric acid secretion activity by histamine. Other pathways for acid secretion remain unprotected. On the other hand, omeprazole blocks the final pathway of acid secretion e.g. histamine, acetylcholine and pentagastrin pathway. Profound acid suppression can prevent aspirin induced gastric mucosal injury in normal subject. This approach may prevent the development of peptic ulcer and their complications in patients taking aspirin and other NSAIDs. Acid inhibition by ranitidine results in a reduction in gastric mucosal damage, but aspirin induced damage is not totally abolished ${ }^{7}$.

In a recent epidemiological study, the use of a PPI was found to be associated with a decrease of $80 \%$ in the risk of upper GI bleeding in a subject taking low dose aspirin $^{8}$. Omeprazole $40 \mathrm{mg}$ daily along with aspirin resulted gastric mucosal bleeding was $85 \%$ less than that in patient taking aspirin alone. Omeprazole appears to be very effective in rendering both acute gastroduodenal mucosal damage and upper GI bleeding in the high risk patients taking low dose aspirin ${ }^{9}$.

In a study, on low dose aspirin and mucosal protective effect of omeprazole and ranitidine by Hossain MD et al in this issue of JAFMC found the superiority of omeprazole over ranitidine. Forty percent patients on ranitidine had mucosal injury; but patients on omeprazole prophylaxis only had $12.5 \%$ mucosal injury. Omeprazole was superior to ranitidine in the protection of gastroduodenal mucosal injuries associated with lowdose aspirin. The superiority of omeprazole over ranitidine in the protection of gastric mucosal injury was observed; but not on duodenal mucosal injury, in which both the omeprazole and ranitidine were equally effective. Major effect of low dose aspirin is on gastric mucosa than duodenal mucosa. The superiority of efficacy of omeprazole over ranitidine is consistent with those reported in most previous studies. In another study by Yeomans et al ranitidine was observed almost ineffective in preventing gastric ulcer ${ }^{10}$.

So omeprazole as prophylaxis may be used in the

1. Maj Gen Md Abdul Moyeed Siddiqui (Retd) MBBS, MCPS, FCPS, FCPS(Pak), FRCPI, FRCP(Eden), FACP(USA), Former-Director General Medical Services, Bangladesh Armed Forces. 
protection of gastric mucosal damage in patients particularly with risk factors taking low dose aspirin for long period of time.

\section{Refernces}

1. Kumar P, Clark M, eds. Clinical Medicine. 6th ed. Spain: Elsevier Book Aid International; 2006. p. 287-8.

2. Taha AS, Angerson WJ, Prasad R, Mccloskey C, Blatchford O. Upper gastrointestinal bleeding and the changing use of COX-2 nonsteroidal anti-inflammatory drugs and low-dose aspirin. Aliment Pharmacol Ther 2007; 26: 1171-1178.

3. Ohmann $\mathrm{C}$, Imhof $\mathrm{M}$, Ruppert $\mathrm{C}$, et al.Time-trends in the epidemiology of peptic ulcer bleeding. Scandinavian Journal of Gastroenterology, 2005; 40: 914-920.

4. Lanza FL, Francis K L Chan FKL, Quigley EMM. Guidelines for Prevention of NSAID-Related Ulcer Complications. The American Journal of Gastroenterology 2009 March; 104 : 728-738.

5. Hart J, Hawkey JC, Lanas A. Predictors of gastroduodenal erosions in patients taking low-dose aspirin. Alimentary Pharmacology \& Therapeutics 2010; 31(1): 143-9.
6. Sancar M, Hantash T, Okuyan B, et al. Comparative effectiveness of Glycyrrhiza glabra vs omeprazole and misoprostol for the treatment of aspirin-induced gastric ulcers. African Journal of Pharmacy and Pharmacology 2009 December; 3(12): 615-620.

7. Daneshmend TK Stein AG, Bhaskar NK, Hawkey CJ. Abolition by Omeprazole of Aspirin induced Gastric mucosal injury in man. Gut 1990; 31;514-17

8. Yeomans ND, Tulassay Z, Juhász L, et al. A comparison of omeprazole with ranitidine for ulcers associated with nonsteroidal antiinflammatory drugs. Acid Suppression Trial: Ranitidine versus Omeprazole for NSAID-associated Ulcer Treatment (ASTRONAUT) Study Group. N Engl J Med. 1998 March 12; 338(1):719-26.

9. Lansa A, Ferrandez A. Treatment and prevention of aspirin induced gastroduodenal ulcers and gastrointestinal bleeding. Expert Opinion Drug Saf 2002 Sep; 1(3) : 245-52.

10. Yeomans ND, Svedberg LE, Naesdal J. Is Ranitidine Therapy Sufficient For Healing Peptic Ulcers Associated With Non-Steroidal Anti-Inflammatory Drug Use? Int J Clin Pract 2006; 60(11): 14011407. 